Cover page 


\title{
The effects of microstructural features on the performance gap in corrosion resistance between bulk and HVOF sprayed Inconel 625
}

\author{
N. Ahmed, M.S. Bakare, D.G. McCartney, K.T. Voisey*. \\ Mechanics, Materials and Structures Research Division, \\ Faculty of Engineering, \\ University of Nottingham, NG7 2RD, UK. \\ *corresponding author, katy.voisey@nottingham.ac.uk, 01159514139
}

\section{Abstract}

It is commonly observed that there is a performance gap between the corrosion resistance of thermally sprayed coatings and the equivalent bulk material. This is attributed to the significantly modified microstructure of the sprayed coatings. However, currently there is no detailed understanding of which aspects of microstructural modification are primarily responsible for this performance gap. In this work several deliberately microstructurally modified versions of the Ni-based superalloy Inconel 625 were produced. These were subjected to potentiodynamic electrochemical testing in $0.5 \mathrm{M} \mathrm{H}_{2} \mathrm{SO}_{4}$ to investigate the links between specific microstructural features and electrochemical behaviour. Samples were prepared by high velocity oxy-fuel (HVOF) thermal spraying, laser surface remelting using a high power diode laser and conventional powder sintering. Microstructural features were examined by optical and scanning electron microscopy and X-ray diffraction.

Potentiodynamic testing was carried out on the following forms of Inconel 625: wrought sheet; HVOF sprayed coatings; sintered powder compacts; laser melted wrought sheet and HVOF sprayed coatings. Using the corrosion behaviour, i.e. passive current density, of the wrought sheet as a baseline, the performance of different forms of Inconel 625 were compared. It is found that a fine dendritic structure (with associated microsegregation) produced by laser remelting wrought sheet has no significant effect on corrosion performance. Up to $12 \%$ porosity in sintered powder samples increases the passive current density by a factor of only around 2. As observed previously, the passive current density of HVOF sprayed coatings is 20 - 40 times greater. However, HVOF coatings subjected to laser surface 
remelting are found to have a passive current density close to that of wrought material. It is concluded that, whilst porosity in coatings produces some decrease in corrosion resistance, the main contributing factor is the galvanic corrosion of localised $\mathrm{Cr}$-depleted regions which are associated with oxide inclusions within HVOF sprayed samples.

Keywords: Inconel 625, HVOF, thermally sprayed coatings, corrosion, electrochemical tests, laser surface melting

PACS codes: 81.65.Kn, 82.45.Jn, 81.15.Rs 


\section{Introduction}

Inconel 625 has long been used in aqueous corrosive environments due to its excellent overall corrosion resistance [1]. According to Neville et al. [2], the passive film that forms on Inconel 625 is a mixed $\mathrm{Fe}-\mathrm{Cr}$ oxide; and protects the material from further corrosion. The ability of wrought Inconel 625 to exhibit passivation at remarkably low current density values during polarisation tests is well established $[3,4]$. However, this is not true of thermally sprayed coatings of Inconel 625; even when deposited by the relatively new high-velocity oxy-fuel (HVOF) technique which tends to produce higher quality coatings with less oxidation and porosity than other thermal spray methods [5]. Zhang et al. [3] studied the aqueous corrosion behaviour of HVOF Inconel 625 coatings, and found that the passive current density of the sprayed coating in $0.5 \mathrm{M} \mathrm{H}_{2} \mathrm{SO}_{4}$ was at least five times higher than that of wrought Inconel 625. Shrestha et al. [6] remarked that thermally sprayed Inconel 625 coatings could, at best, match the performance of wrought stainless steel.

This difference in corrosion performance is generally attributed to the inhomogeneous coating structure primarily caused by pores and oxides formed during coating deposition, as well as the elemental segregation arising from the rapidly solidified structure. However, there are contrasting views in the literature about the effects of these microstructural modifications on the corrosion behaviour. For example, Shrestha et al. [6] found a more highly oxidised Inconel 625 coating to possess poorer corrosion resistance; whereas Zhang et al. [3] noted that Inconel 625 coatings with the lowest oxide content did not give the lowest current density values. The contribution of porosity is also contentious; according to Neville et al. [4], it is no longer a major corrosion issue for the HVOF process because porosity levels are typically less than $1-2 \%$ in coatings deposited under optimised conditions. Due to the nature of thermal spray processes porosity and oxidation tend to occur immediately adjacent to each other [7], making it difficult to determine the independent effect of each on corrosion performance. 
In an effort to further improve the corrosion behaviour of coatings, a number of researchers have investigated the use of laser surface melting (LSM) [8-11]. LSM of thermally sprayed coatings has been shown to be able to significantly improve corrosion performance. This improvement is attributed to elimination of interconnected porosity as well as a general homogenisation of the structure $[8,9]$. However, some LSM treatments produce no significant effects on corrosion performance [10] and in other cases LSM effects, such as the inhomogeneities produced by overlapping tracks, can degrade corrosion resistance [11].

The aim of the present work was to provide a more detailed understanding of how specific microstructural features result in the observed performance gap between bulk and sprayed Inconel 625. In this study, a number of microstructurally modified versions of Inconel 625 were produced namely: wrought (no oxides, no porosity), thermally sprayed coatings (oxides and porosity), sintered (porosity, no oxides), laser melted wrought (rapidly solidified structure largely free from oxides, no porosity) and laser melted thermally sprayed coatings (rapidly solidified structure with loss of some oxide forming elements, no oxides, no porosity). Potentiodynamic electrochemical testing was carried out in order to investigate links between specific microstructural features and electrochemical behaviour.

\section{Experimental procedures}

\subsection{Materials}

Wrought Inconel 625 (UNS N06625) was obtained in the form of $5 \mathrm{~mm}$ thick cold rolled annealed sheet from Special Metals Corporation. Gas-atomised Inconel 625 powder for HVOF spraying with nominal size range $-53+20 \mu \mathrm{m}$ was used (Praxair Ni 328-5/T1265F). Table i gives the composition of the material in wrought and powder form showing slight differences (mainly in Fe content). The composition of the wrought material is as determined by spark emission spectroscopy whereas that of the powder is from a certificate of analysis provided by the suppliers. 


\subsection{High-velocity oxy-fuel spraying}

A MetJet-II liquid fuel HVOF system (Metallisation Limited, Dudley, UK) was used to deposit the coatings. In the MetJet system kerosene is used as liquid fuel and is combusted with oxygen to produce a hot gas jet into which the powder particles are radially injected using nitrogen as the carrier gas. The operation of the gun and detailed arrangement for spraying are described in detail elsewhere [3]. The majority of the coatings were sprayed onto mild steel coupons $(60 \times 25 \times 5 \mathrm{~mm})$, although a small number were sprayed onto $5 \mathrm{~mm}$ thick wrought Inconel 625 sheet for a specific set of corrosion experiments. All substrates were grit blasted and degreased prior to deposition. The spraying parameters used are given in Table ii, typically 30 passes of the spray gun were required at a traverse speed of $1 \mathrm{~m} \mathrm{~s}^{-1}$ to achieve coatings with a thickness of approximately $350 \mu \mathrm{m}$.

\subsection{Sintered samples}

The same $-53+20 \mu \mathrm{m}$ Inconel 625 powder used for HVOF spraying was also used to produce the sintered samples. The powder was compacted to produce green pellets by using a single action uniaxial hydraulic press at a compaction pressure of $800 \mathrm{MPa}$. Prior to compaction, the wall of the $22 \mathrm{~mm}$ diameter die was lubricated with lithium stearate mixed with acetone in order to reduce the frictional losses at the wall of the die and also to ensure easy removal of the compacted pellet. 13 grams of Inconel 625 powder were used to form each sample.

The compacted specimens were sintered in a laboratory type silicon carbide resistance heated tubular furnace in a flowing argon environment with a flow rate of approximately $0.21 \mathrm{~min}^{-1}$. Flowing argon gas was used throughout the heating, isothermal sintering and cooling of the materials to avoid any form of oxidation. Samples were sintered at either of two temperatures, $1310^{\circ} \mathrm{C}$ and $1325^{\circ} \mathrm{C}$, for 60 minutes. The heating rate was $20 \mathrm{~K} \mathrm{~min}^{-1}$ followed by isothermal holding at the selected temperature for 60 minutes and furnace cooling. Pellets weighing $13 \mathrm{~g}$ and $5 \mathrm{~mm}$ in height were obtained after sintering. 
The density of the sintered samples was obtained by measuring the mass and dimensions of the samples. Porosity was calculated by comparing the density of the sintered samples, $\rho_{\text {sample, }}$, with the bulk density of Inconel $625, \rho_{\text {bulk, }}$, as shown in Eqn1.

$$
\text { Porosity }=\frac{\rho_{\text {bulk }}-\rho_{\text {sample }}}{\rho_{\text {bulk }}} \times 100 \% \quad \text { Eqn. } 1
$$

It should be noted that the pores in the sintered samples are not connected, hence the porosity is referred to as non-interconnected porosity.

\subsection{Laser surface melting}

Laser melting was carried out by an industrial high power diode laser (HPDL)

ROFIN-SINAR DL 025, with maximum power of $2.2 \mathrm{~kW}$ and a wavelength of $940 \pm 10 \mathrm{~nm}$. The laser head was stationary, with the beam vertically incident on the samples which were clamped to a CNC controlled x-y table. Both wrought Inconel 625 and the thermally sprayed coatings were laser treated within an Ar gas environment. A rectangular beam $(6 \times 3 \mathrm{~mm})$ was focused on the surface so that the relative movement of the laser and samples produced $\sim 6 \mathrm{~mm}$ wide melt-tracks. The laser power was kept constant at $1500 \mathrm{~W}$, the scan speed was varied in the range of 500-2000 $\mathrm{mm} \mathrm{min}^{-1}$ in order to generate resolidified structures with a range of secondary dendrite arms spacings.

\subsection{Electrochemical tests}

Electrochemical performance was evaluated by potentiodynamic tests in an acidic, $0.5 \mathrm{M}$ $\mathrm{H}_{2} \mathrm{SO}_{4}$, electrolyte. A three electrode cell was employed using methods similar to ASTM G594 and G61-86 test procedures. The sample, mounted in non-conductive resin, was ground to a 600-grit finish on SiC paper and had an area of $100 \mathrm{~mm}^{2}$ exposed to the electrolyte which was maintained at $30{ }^{\circ} \mathrm{C}$. The electrolyte was deaerated by nitrogen gas purging for at least 30 minutes prior to sample immersion. Upon immersion of the sample, the nitrogen gas tube was held above the electrolyte surface to keep the environment free from oxygen. Thus the experiments were conducted in oxygen free static conditions to avoid the disturbance caused 
by stirring the electrolyte. The sample (working electrode, WE) was allowed to stabilise for 60 minutes before polarising the potential against a reference saturated calomel electrode (SCE). Using a potentiostat (ACM Instruments, Cumbria UK), a potentiodynamic polarisation scan was performed with a sweep rate of $20 \mathrm{mV} \mathrm{min}^{-1}$ from $250 \mathrm{mV}$ below the 1-hour open circuit potential to a limiting current density value of $10^{5} \mathrm{~mA} \mathrm{~m}^{-2}$ to see the progression of corrosion in the samples. The corresponding current flow between the WE and a flag-type platinum counter electrode (CE) was recorded. The reproducibility of the passive current density results was determined, by repeated measurements on wrought sheet samples, as $\pm 9 \mathrm{~mA} \mathrm{~m}^{-2}$. Selected samples were polished to a $1 \mu \mathrm{m}$ surface finish for subsequent microscopic examination following removal from the solution at the end of the polarisation scan.

\subsection{Characterisation}

Microstructural examination was performed using optical and scanning electron microscopy (SEM; FEI XL30 with an energy dispersive X-ray analysis system). X-ray diffraction (XRD) was also used to identify phases present, this was carried out using a Siemens D500 diffractometer with $\mathrm{CuK}_{\alpha}$ radiation. In addition, a JEOL JXA-8200 SuperProbe electron probe microanalyser (EPMA) was used for microchemical analysis including that of oxygen using wavelength dispersive X-ray spectroscopy (WDS). Wherever required, the samples following grinding and polishing, were etched by immersing in aqua-regia solution ( 3 parts $\mathrm{HCl}, 1$ part $\mathrm{HNO}_{3}$ ) at a temperature of $\sim 35^{\circ} \mathrm{C}$ for $\sim 10$ s.

\section{Results}

\subsection{Microstructure of wrought Inconel 625}

The microstructure of the wrought alloy is shown in the optical micrograph of Figure 1. Heavily etched grain boundaries are clearly visible along with sub-grains and twins present due to the prior cold rolling and annealing. A small quantity of second phase particles was 
also found to be present as shown in Figure 1b. Energy dispersive X-ray analysis (EDX) in the SEM indicated that these were rich in $\mathrm{Ti}$ and $\mathrm{Nb}$ and so were most likely to be carbides, nitrides or carbonitrides.

The XRD pattern obtained from the wrought sheet is shown in Figure 2 and the peaks can be indexed as a face centred cubic structure, this is $\gamma$-Ni as expected for a Ni-based alloy. The peaks are seen to be of small angular width and no other phases could be detected in the XRD pattern.

\subsection{Microstructure of laser treated wrought material}

Laser melting of wrought material resulted in the rapidly solidified microstructure featuring aligned dendrites, as shown in Figure 3. The micrographs were obtained from a section taken parallel to the beam traverse direction. Evidently the dendrites have solidified with the $<100\rangle$ growth direction tilted towards the moving heat source which is a typical solidification pattern for laser surface melting and welding $[12,13]$. The measured secondary dendrite arm spacings (SDAS) are included in Table iii and indicate that, as expected, SDAS decreases with increasing traverse speed i.e. with increasing cooling rate.

\subsection{Microstructure of HVOF thermally sprayed coatings of Inconel 625}

The as-sprayed coating was $\sim 350 \mu \mathrm{m}$ thick (Figure $4 \mathrm{a}$ ). The coating had a characteristic thermally sprayed microstructure, resulting from the successive deposition of individual powder particles (Figure 4b). Figure $4 \mathrm{c}$ shows a dendritic microstructure in the deformed particles, this was a retained microstructure from the gas atomised feedstock powder. Figure 4 c also shows that the coating is seen to comprise of deformed, near-spherical particles $(\mathrm{P})$ as well as lamellar splat-like features (L). These arise from the impact and solidification of partially and fully melted powder particles respectively. The microstructure observed is characteristic of coatings produced by this type of liquid fuel gun as discussed elsewhere [3]. 
As well as the distinctive lamellar structure the coating showed other microstructural features typical of thermal sprayed coatings, namely pores and oxides. The presence of oxides in the thermally sprayed coatings was verified by XRD (Figure 2). The HVOF coatings contained peaks of $\mathrm{Cr}_{2} \mathrm{O}_{3}$, not observed in the wrought case. The strong peak at $\sim 44^{\circ}$ resulting from the $\gamma$ Ni face centre cubic matrix was broader in the coating compared with the wrought material. This is due to a combination of fine grain size and/or microstrain within the material [14]. Figure $5 \mathrm{a} \& \mathrm{~b}$ are secondary electron SEM images indicating the oxide rich area of the coating which was examined with EPMA. Figure 5(c) - (f) show elemental concentration maps of this region for the elements $\mathrm{O}, \mathrm{Ni}, \mathrm{Cr}$ and $\mathrm{Nb}$ respectively. In the top right and bottom left corners of this region are areas which correspond to unmelted particles. The central region results from resolidification of molten material and is seen to have a nonuniform structure and composition with high levels of oxygen indicating oxide formation. The concentration maps reveal a clear association of high $\mathrm{Cr}$ and $\mathrm{O}$ concentrations which confirm the location of the $\mathrm{Cr}_{2} \mathrm{O}_{3}$ phase in this interparticle and/or intersplat region. There is also clear evidence for significant $\mathrm{Cr}$ and $\mathrm{Nb}$ depletion in the metallic regions in this area.

\subsection{Microstructure of laser-treated coatings of Inconel 625}

Laser surface melting of HVOF coatings resulted in a structure which was free from the pores and oxides found in the as-sprayed condition (Figure 6). The low magnification optical micrograph in Figure 6a shows that the coating was melted to a depth of approximately $200 \mu \mathrm{m}$ and that melting was confined to the coating, avoiding any coating/substrate mixing. Porosity was eliminated on resolidification and any pre-existing oxides floated and accumulated at the top surface. This top surface, and hence the accumulated oxide, was removed by grinding before corrosion testing. Rapid solidification following laser surface melting produced the dendritic structure as shown in Figure 6b, this is identical to that previously seen in the laser melted wrought material (Figure 3). EDX revealed that bright interdendritic areas were enriched in $\mathrm{Nb}$ and $\mathrm{Mo}$, while $\mathrm{Cr}$ content remained almost uniform 
throughout the laser melted structure. The SDAS values were, within experimental error, identical to those obtained for the laser melted wrought material.

The XRD pattern of the laser melted coating (after the top surface had been removed by grinding) is shown in Figure 2. No oxide peaks are evident, confirming that the oxide present in the as-sprayed coating was removed.

\subsection{Microstructure of sintered samples}

The average porosity of the sintered samples was $12 \%$ and $6 \%$ for isothermal sintering at $1310^{\circ} \mathrm{C}$ and $1325^{\circ} \mathrm{C}$ respectively. No oxide peaks were detected in the XRD spectra of the sintered samples (Figure 2). The etched SEM micrograph shown in Figure 7 shows that the marked segregation present in the as-sprayed coating and the laser treated material (Figure 3,Figure 5 Figure 6) is absent from the sintered samples. It is also clear that the pores had a near-spherical morphology with diameters $\sim 15-30 \mu \mathrm{m}$. Oxide peaks were not seen in the XRD spectra of the sintered material (Figure 2).

\subsection{Potentiodynamic tests}

Figure 8 shows potentiodynamic scans in $0.5 \mathrm{M} \mathrm{H}_{2} \mathrm{SO}_{4}$ for the various forms of Inconel 625 . Passive current density values, Ip, are listed in Table iii the current densities correspond to a potential of $450 \mathrm{mV} \mathrm{SCE}$, within the passive region. This potential was chosen as it was well within the passive range for all samples considered here.

In Figure 8a the corrosion behaviour of wrought and laser melted wrought material, with a traverse speed of $1000 \mathrm{~mm} \mathrm{~min}^{-1}$, are seen to be almost identical with only a small difference in behaviour just above Ecorr. The average passive current density measured for the wrought material was $22 \pm 9 \mathrm{~mA} \mathrm{~m}^{-2}$. This therefore indicates that the fine scale dendritic structure with associated microsegregation had a negligible influence on corrosion behaviour. Figure $8 \mathrm{~b}$ compares the wrought material with that of sintered samples with different degrees of porosity. The porosity did not affect the Ecorr value but is seen to increase Ip; increased 
porosity caused a greater increase in Ip. In Figure 8c the behaviour of wrought material, assprayed HVOF coating and laser melted coating are compared. The laser melted coating results are from a sample melted using a traverse speed of $1000 \mathrm{~mm} \mathrm{~min}^{-1}$. The as-sprayed HVOF coating had a lower Ecorr valued and a significantly larger Ip; about 40 times that of the wrought material. This is similar to previously measured differences in $\mathrm{H}_{2} \mathrm{SO}_{4}$ [3]. Finally, in Figure 8d the behaviour of as-sprayed coatings on mild steel and Inconel 625 and a debonded coating are compared. All previous coating results relate to deposits on mild steel and the aim of this set of results was to identify any contribution of the substrate to the polarisation results. The differences in behaviour are small and within the experimental scatter observed for a batch of as-sprayed coatings. Therefore, it can be concluded that there is not a significant contribution from a mild steel substrate. For comparison, the polarisation curve for mild steel in the same solution is also displayed.

\subsection{Characterisation of as-sprayed coatings after polarisation}

Figure 9 presents as-sprayed coatings after polarisation to $10^{4}$ and $10^{5} \mathrm{~mA} \mathrm{~m}^{-2}$ respectively. In each micrograph the central, circular feature is an unmelted powder particle within the coating. It was observed that the particle boundary regions started to corrode preferentially (Figure 9a). When current density values were increased, these areas became more heavily corroded and corrosion of the internal structure of the splats occurred (Figure 9b).

\section{Discussion}

The potentiodynamic results shown in Figure $8 \mathrm{c}$ confirm the performance gap between bulk Inconel 625 and the HVOF Inconel 625 coating. It can also be seen that laser surface melting of the sprayed coating largely eliminates the performance gap. However, laser melting of the coating, followed by resolidification, simultaneously changes several aspects of the microstructure: porosity is eliminated on resolidification; oxides float and accumulate on the top surface and are thereby removed from the material; the resolidified material gains a 
rapidly solidified microstructure replacing the original mixture of unmelted and resolidified regions. To determine the effects of specific microstructural features, the potentiodynamic results from the various deliberately modified microstructures of Inconel 625 (Figure 8) must be considered.

The nature of the thermal spray process dictates that porosity is always found in the coating structure. Interconnected porosity may compromise the effectiveness of the coating as a barrier to corrosive species. In order to identify any effect due to interconnected porosity, three versions of the HVOF coatings were tested: HVOF coating on a mild steel substrate; HVOF coating on an Inconel 625 substrate; free-standing HVOF coating. The similarity of the polarisation curves (Figure 8d) for all three coating systems indicated the absence of any such effect. This might be due either to the absence of interconnected porosity, or for there being insufficient time for the electrolyte to reach the substrate through any interconnected porosity during the course of the potentiodynamic tests $(\sim 2 \mathrm{~h})$. In either case, the results confirmed that the observed polarisation behaviour in these tests was due to the coating itself and was independent of the substrate, i.e. no effects due to interconnected porosity were seen. The similarity in behaviour of wrought and laser treated wrought samples (Figure 8a) reveals that the presence of a rapidly solidified microstructure does not have any significant effect on electrochemical behaviour. Therefore it can also be stated that the observed microsegregation (Figure 3Figure 6) resulting from rapid solidification has no significant effect on electrochemical behaviour.

For both laser treated coatings and laser treated wrought material, the secondary dendrite arm spacing has a negligible effect. Although the average passive current density value seemed to increase with secondary dendrite arm spacing for laser treated wrought material (Table iiiTable ), the magnitude of the variation is comparable to the scatter in experimental data. While further experiments could determine if this is a real effect, it is clear that for the 
material studied in this work the effect of secondary dendrite arm spacing is insignificant in comparison to the other microstructural features considered.

It has already been established that there are no effects due to interconnected porosity in the coatings considered in this work. However, non-interconnected porosity is clearly present in the coatings and may affect their corrosion behaviour via crevice corrosion. The potentiodynamic scans presented in Figure $8 \mathrm{~b}$ show that the passive current density decreases as the level of porosity decreases. This indicates that at least part of the improvement in corrosion behaviour observed after laser surface melting of coatings is due to elimination of porosity. It is suggested that the presence of porosity increases the passive current density due to crevice corrosion occurring in the pores. Elimination of the porosity eliminates this mechanism of corrosion, hence improving corrosion resistance.

However, the improvement due to laser surface melting is far greater than that resulting from reducing porosity levels from $12 \%$ to zero. Another aspect, or aspects, of the microstructural modifications arising from laser surface melting must therefore be the main cause of the observed improved corrosion behaviour.

Examination of samples after potentiodynamic testing (Figure 9) clearly show that corrosion is preferentially occurring in the regions between adjacent splats. These regions have a complex heterogeneous microstructure (Figure 5) including a mixture of nonmelted and resolidified material, oxidised regions and porosity. Laser surface melting eliminates all of these features. The extent of the role of porosity has already been identified. The relative effects of the mixture of nonmelted and resolidified material and oxidised regions on the corrosion performance gap now need to be examined.

The presence of $\mathrm{Cr}_{2} \mathrm{O}_{3}$ in the as-sprayed coatings means that there will have been some depletion in the $\mathrm{Cr}$ content of the remaining metallic coating since some of the original $\mathrm{Cr}$ will have been consumed by oxidation during coating deposition. Laser surface melting of as-sprayed coatings removes oxides generated during spraying since these float to and 
accumulate at the top surface when the coating is melted by the laser. This top, oxide rich, layer is ground away before potentiodynamic testing. The material tested is oxide free but will be uniformly slightly $\mathrm{Cr}$ depleted. Figure $8 \mathrm{c}$ shows that laser surface melting of coatings largely, but not completely, eliminates the performance gap. The passive current density seen for laser treated coatings is still higher than that of the wrought material. The laser treated coating has a rapidly solidified microstructure and, as explained above, will be slightly depleted in $\mathrm{Cr}$. The presence of a rapidly solidified microstructure has already been shown to have no significant effect on the observed potentiodynamic results. The minor $\mathrm{Cr}$ depletion is therefore attributed to be the cause of the higher passive current density of laser treated coatings compared to the wrought material.

Porosity and Cr depletion have both been shown to make some contribution to the observed performance gap. However the magnitude of the performance gap has yet to be explained.

While both as-sprayed and laser treated coatings are both $\mathrm{Cr}$ depleted, the $\mathrm{Cr}$ depletion is localised in the as-sprayed coatings whereas it is uniform in the laser treated coatings. This is because during coating deposition the feedstock powder particles are partially molten and it is only this molten outer layer that undergoes oxidation. However, because the oxide forms on molten material, there is no classic depletion profile under the oxide. Rapid diffusion occurs in the molten material, and hence the molten material is instead uniformly depleted. On impact and resolidification this results in the resolidified material being depleted in $\mathrm{Cr}$ whereas the nonmelted material retains the original $\mathrm{Cr}$ content. This results in a microstructure consisting of regions of varying $\mathrm{Cr}$ content. Formation of galvanic cells is therefore possible. Galvanic corrosion of the $\mathrm{Cr}$ depleted resolidified material is consistent with the observation that the resolidified intersplat material undergoes preferential corrosion. This form of corrosion will be eliminated by laser surface melting of coatings since the regions of localised $\mathrm{Cr}$ depletion are eliminated. It is therefore suggested that it is elimination of this form of corrosion that is the main reason why laser surface melting is improving the 
corrosion resistance of the coatings considered here. It is also suggested that this galvanic corrosion is the main reason behind the performance gap between the thermally sprayed coatings and the wrought material.

\section{Conclusions}

- The performance gap between bulk and HVOF sprayed Inconel 625 is largely due to galvanic corrosion between $\mathrm{Cr}$ depleted resolidified regions and non-melted material in the coatings.

- The presence of non-interconnected porosity is detrimental to the corrosion resistance of the as-sprayed coatings.

- Laser surface melting of HVOF coatings of Inconel 625 largely eliminates the performance gap due to the elimination of both porosity and localised regions of material depleted in Cr.

- No effects due to the presence of interconnected porosity were observed.

- The corrosion behaviour of Inconel 625 is not significantly changed by the introduction of a rapidly solidified microstructure.

- The corrosion behaviour of Inconel 625 is insensitive to the range of secondary dendrite arm spacings investigated in this work. 


\section{References}

[1] P. Ganesan, C. M. Renteria, and J. R. Crum, Verstile corrosion resistance of Inconel 625 in various aqueous and chemical processing environments, TMS, Pittsburgh, Pennsylvania, USA, 1991.

[2] A. Neville and T. Hodgkiess, British Corrosion Journal, 35 (2000) 183-188.

[3] D. Zhang, S. J. Harris, and D. G. McCartney, Mat Sci Eng A, 344 (2003) 45-56.

[4] A. Neville, J. M. Perry, T. Hodgkiess, and H. P. Chau, Proc Instn Mech Engrs, 214 (2000) 41-48.

[5] M. M. Helali and M. S. J. Hashmi, Proc of the $10^{\text {th }}$ Conference of the Irish Manufacturing Committee, Galway, Ireland, (1992) 377-387.

[6] S. Shrestha and A. J. Sturgeon, Surface Engineering, 20 (2004) 237-243.

[7] R. W. Smith and R. Knight, JOM. 47 (1995) 32-29.

[8] J. Tuominen, P. Vuoristo, T. Mäntylä, S. Ahmaniemi, J. Vihinen, and P. H. Andersson, J Thermal Spray Tech, 11 (2002) 233-243.

[9] J. Tuominen, P. Vuoristo, T. Mäntylä, M. Kylmälahti, J. Vihinen, and P. H. Andersson, J Thermal Spray Tech. 9 (2000) 513-519.

[10] Z. Liu, J. Cabero, S. Niang, and Z. Y. Al-Taha, Surf Coat Tech. 201 (2007) 71497158.

[11] Z. Liu, P. H. Chong, and P. Skeldon, Surf Coat Tech. 200 (2006) 5514-5525.

[12] S. A. David, S. S. Babu, and J. M. Vitek, JOM. 55 (2003) 14-20.

[13] K. A. Mumtaz, P. Erasenthiran, and N. Hopkinson, J Mat Proc Tech. 195 (2008) 7787.

[14] B. D. Cullity and S. R. Stock, Elements of X-ray diffraction, Prentice Hall, 2001. 
Tables

Table i: Chemical composition of Inconel 625, weight percent

\begin{tabular}{|l|l|l|l|l|l|l|l|l|l|l|l|l|}
\hline & $\mathrm{Ni}$ & $\mathrm{Cr}$ & $\mathrm{Mo}$ & $\mathrm{Nb}$ & $\mathrm{Fe}$ & $\mathrm{C}$ & $\mathrm{Mn}$ & $\mathrm{Si}$ & $\mathrm{Mg}$ & $\mathrm{Al}$ & $\mathrm{Ti}$ & $\mathrm{Co}$ \\
\hline Wrought & 62.9 & 21.8 & 8.9 & 3.42 & 2.44 & 0.01 & 0.05 & 0.07 & 0.01 & 0.1 & 0.2 & 0.1 \\
\hline Powder & 65.1 & 22.0 & 9.0 & 3.43 & 0.01 & 0.01 & 0.1 & 0.2 & - & - & - & 0.15 \\
\hline
\end{tabular}


Table ii: HVOF spraying parameters

\begin{tabular}{|l|l|l|l|l|l|l|}
\hline $\begin{array}{l}\text { Oxygen } \\
\text { flow rate } \\
(\mathrm{l} / \mathrm{min})\end{array}$ & $\begin{array}{l}\text { Kerosene } \\
\text { flow rate } \\
(\mathrm{ml} / \mathrm{min})\end{array}$ & $\begin{array}{l}\text { Nitrogen } \\
\text { flow rate } \\
(1 / \mathrm{min})\end{array}$ & $\begin{array}{l}\text { Powder } \\
\text { feed } \\
\text { rate } \\
(\mathrm{g} / \mathrm{min})\end{array}$ & $\begin{array}{l}\text { Chamber } \\
\text { pressure } \\
(\mathrm{bar})\end{array}$ & $\begin{array}{l}\text { Nozzle } \\
\text { length } \\
(\mathrm{mm})\end{array}$ & $\begin{array}{l}\text { Spray } \\
\text { distance } \\
(\mathrm{mm})\end{array}$ \\
\hline 910 & 480 & 5 & 80 & 7.8 & 100 & 350 \\
\hline
\end{tabular}


Table iii: Passive current density values measured for all samples, results correspond to a potential of $450 \mathrm{mV}$ with respect to a saturated calomel electrode.

\begin{tabular}{|c|c|c|c|}
\hline Sample & $\begin{array}{l}\text { Speed } \\
\left(\mathrm{mm} \mathrm{min}{ }^{-1}\right)\end{array}$ & $\begin{array}{l}\text { Secondary } \\
\text { dendrite } \\
\text { arm spacing } \\
(\mu \mathrm{m})\end{array}$ & $\begin{array}{l}\text { Passive current } \\
\text { density, } 450 \mathrm{mV} \\
\mathrm{SCE}\left(\mathrm{mA} \mathrm{m}^{-2}\right) \pm 9\end{array}$ \\
\hline Wrought material & & & 22 \\
\hline As-sprayed coating on mild steel & & & 492 \\
\hline As-sprayed coating on Inconel 625 & & & 326 \\
\hline Free standing coating & & & 634 \\
\hline Sintered sample $6 \%$ porosity & & & 34 \\
\hline Sintered sample $12 \%$ porosity & & & 54 \\
\hline Laser melted wrought & 500 & $2.4 \pm 0.3$ & 15 \\
\hline Laser melted wrought & 1000 & $1.9 \pm 0.2$ & 24 \\
\hline Laser melted wrought & 1500 & $1.5 \pm 0.3$ & 33 \\
\hline Laser melted wrought & 2000 & $1.3 \pm 0.1$ & 36 \\
\hline Laser melted coating & 500 & $2.5 \pm 0.3$ & 33 \\
\hline Laser melted coating & 1000 & $1.9 \pm 0.3$ & 29 \\
\hline Laser melted coating & 1500 & $1.7 \pm 0.1$ & 37 \\
\hline
\end{tabular}




\section{Figure captions}

Figure 1: Optical micrograph of etched wrought Inconel 625; (a) low magnification showing grain structure (b) higher magnification.

Figure 2: XRD patterns of the different forms of Inconel 625 used: wrought, sintered, assprayed HVOF coating, laser treated HVOF coating after surface grinding to remove accumulated oxides.

Figure 3: SEM secondary electron micrographs showing the rapidly solidified microstructure of laser melted wrought Inconel 625, arrows indicate the beam traverse direction (a) $500 \mathrm{~mm}$ $\min ^{-1}$ (b) $2000 \mathrm{~mm} \mathrm{~min}^{-1}$.

Figure 4: HVOF thermally sprayed Inconel 625 coating (a) SEM secondary electron micrograph showing full coating thickness (b) optical micrograph showing the individual splats from which the coating is formed (c) SEM secondary electron micrograph showing the retained dendritic structure in deformed particles $(\mathrm{P})$ as well as lamellar splat-like features (L).

Figure 5: Oxide rich region in as-sprayed coating and EPMA maps for various elements for the same area.

Figure 6: Microstructure of coating after laser surface melting with a scan speed of $1000 \mathrm{~mm}^{-1}$. (a) optical micrograph, (b) secondary electron SEM image of the area indicated.

Figure 7: Secondary electron SEM images of an etched sample after sintering at $1325^{\circ} \mathrm{C}$.

Figure 8: Potentiodynamic scans (a) wrought and laser melted wrought material, (1000 $\mathrm{mm} \mathrm{min}^{-1}$ traverse speed); (b) sintered samples with different levels of porosity; (c) wrought, as-sprayed HVOF coating and laser melted HVOF coating (1000 $\mathrm{mm} \mathrm{min}^{-1}$ traverse speed); (d) HVOF coated Inconel 625, HVOF coated mild steel, free standing HVOF coating and uncoated mild steel.

Figure 9: As-sprayed HVOF coatings after polarisation; (a) to $10^{4} \mathrm{~mA} \mathrm{~m}^{-2}$, (b) to $10^{5} \mathrm{~mA} \mathrm{~m}^{-2}$. 
Figures

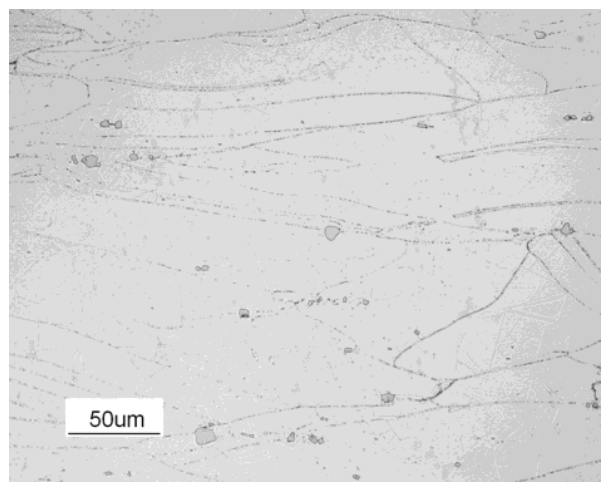

$1 a$ 


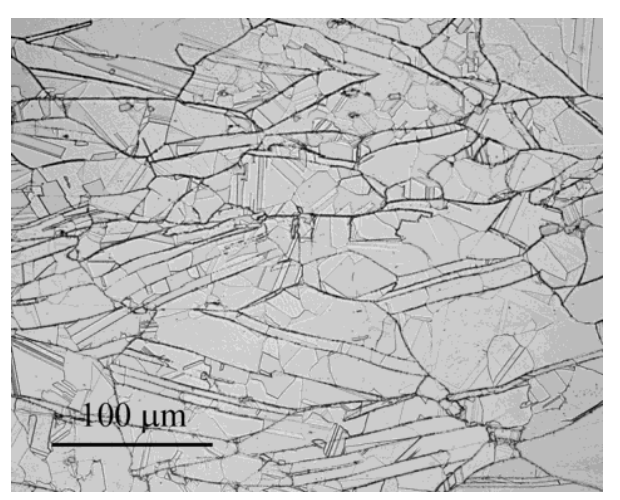




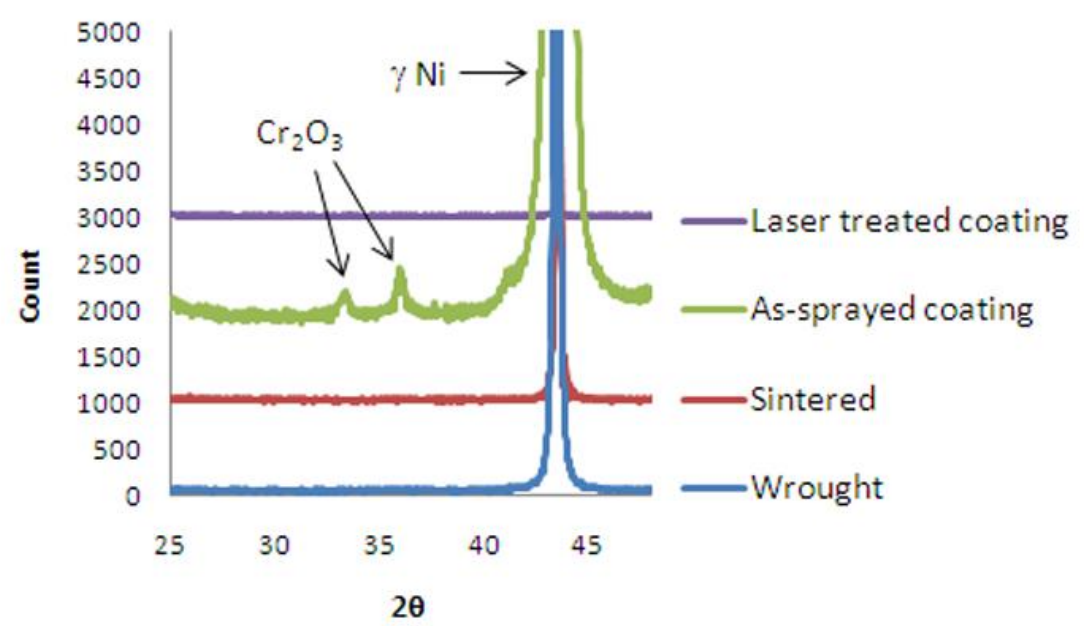




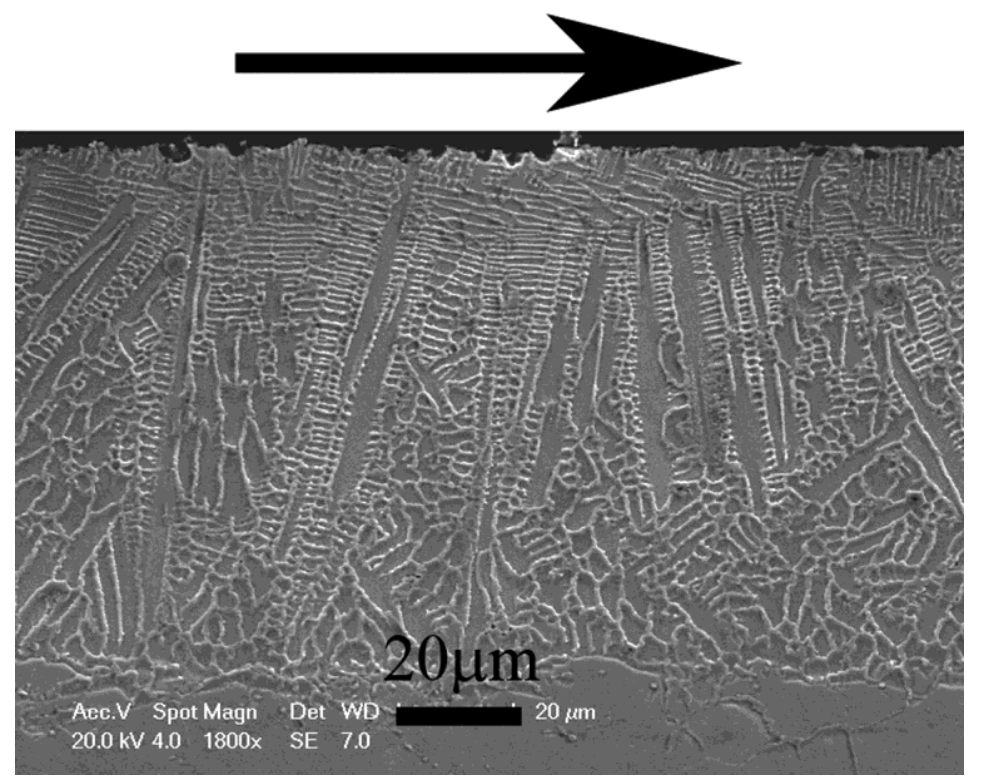




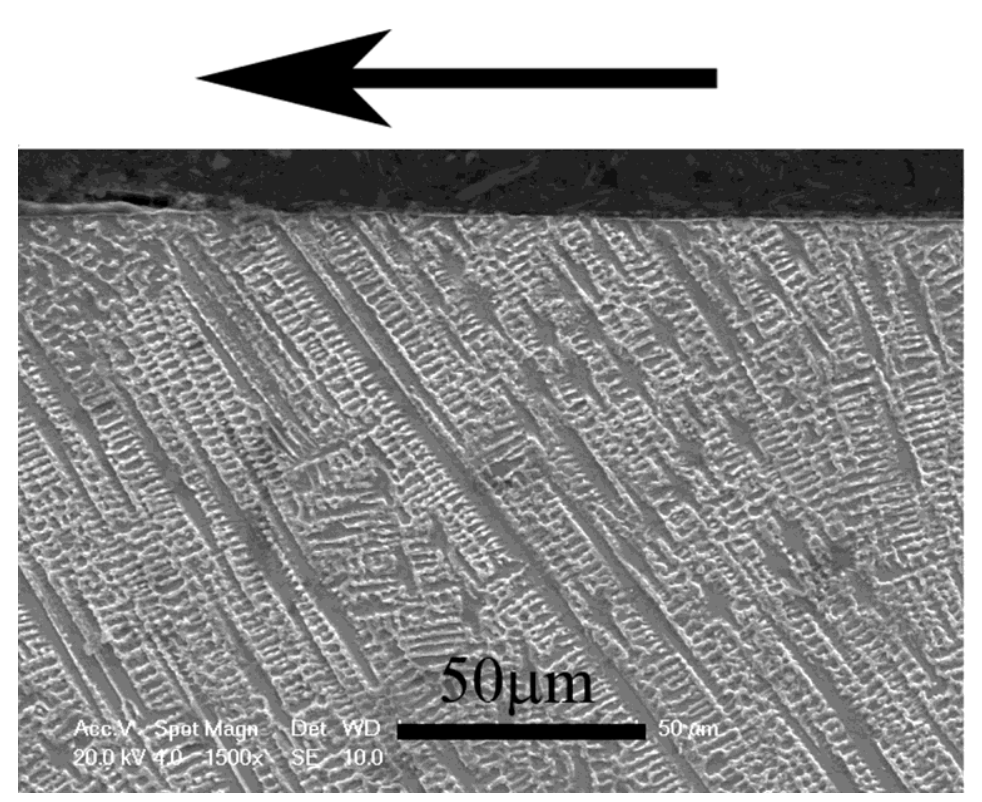




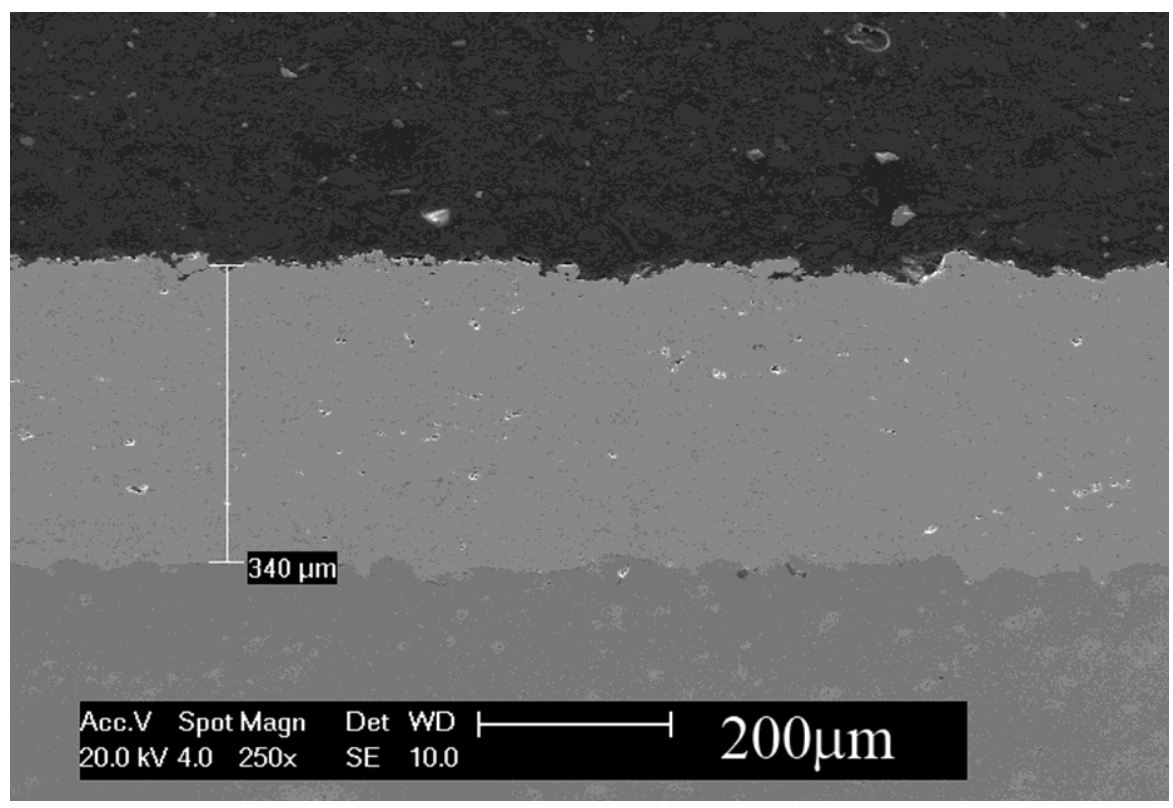




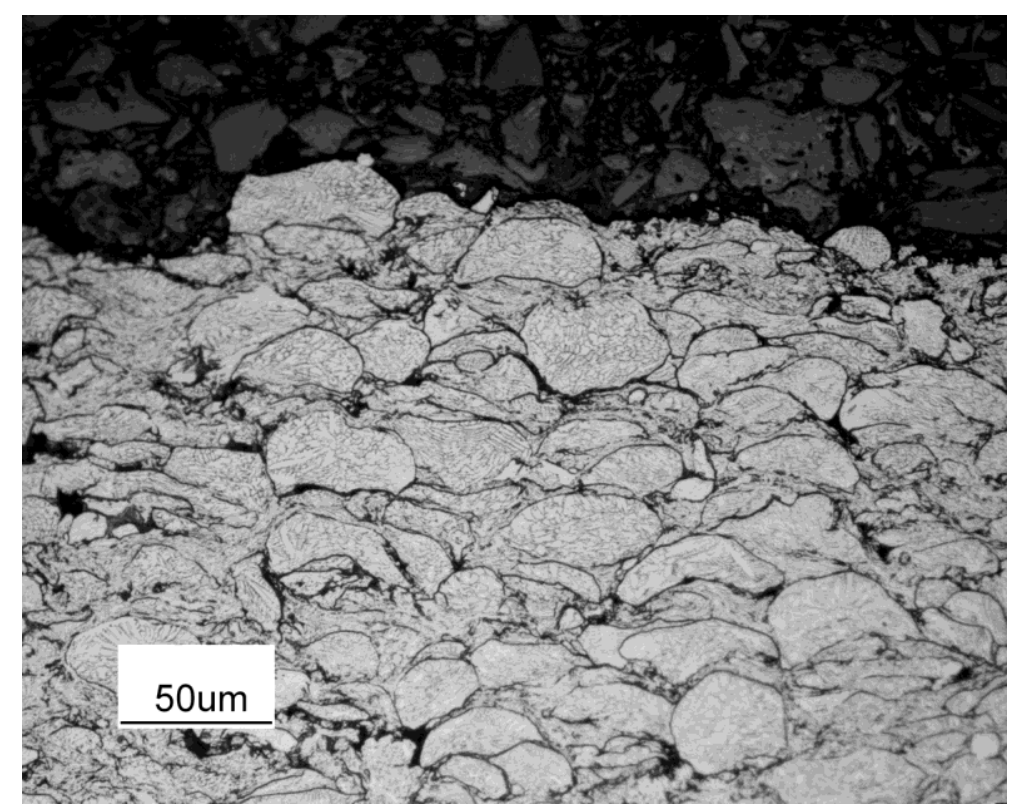




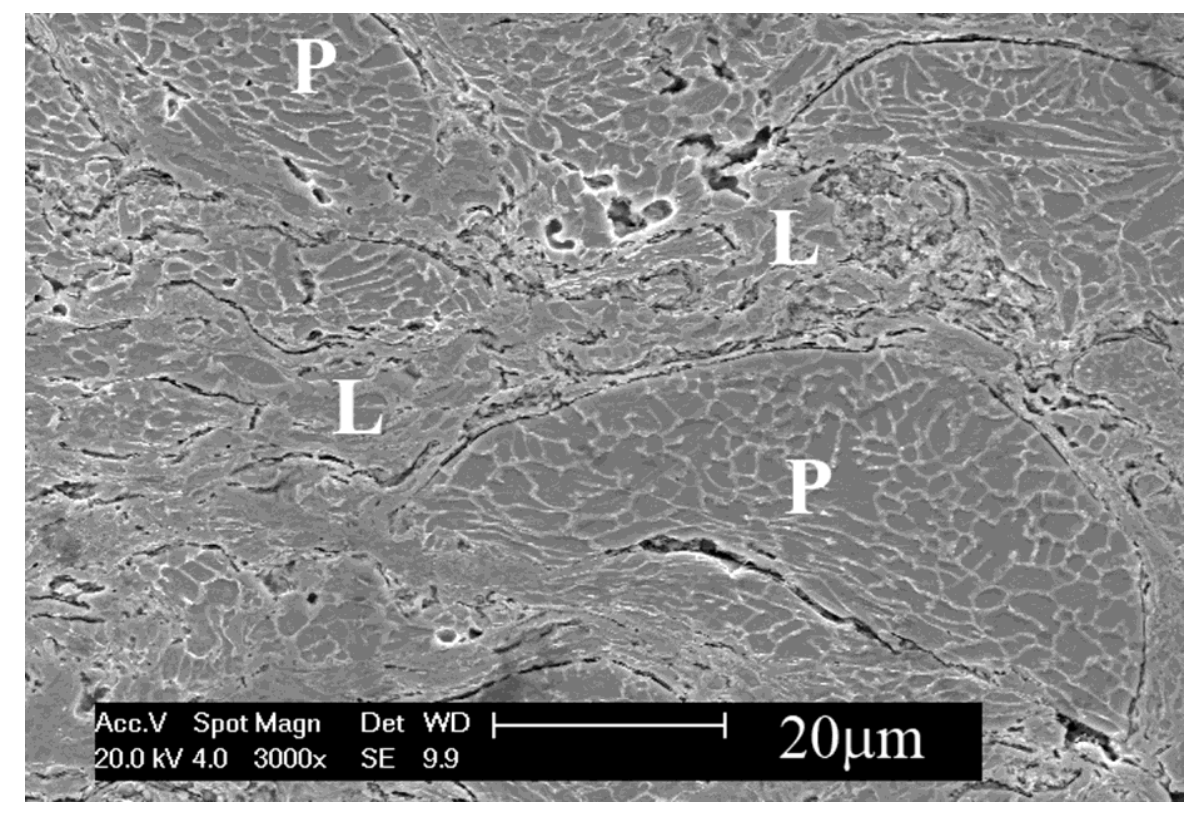




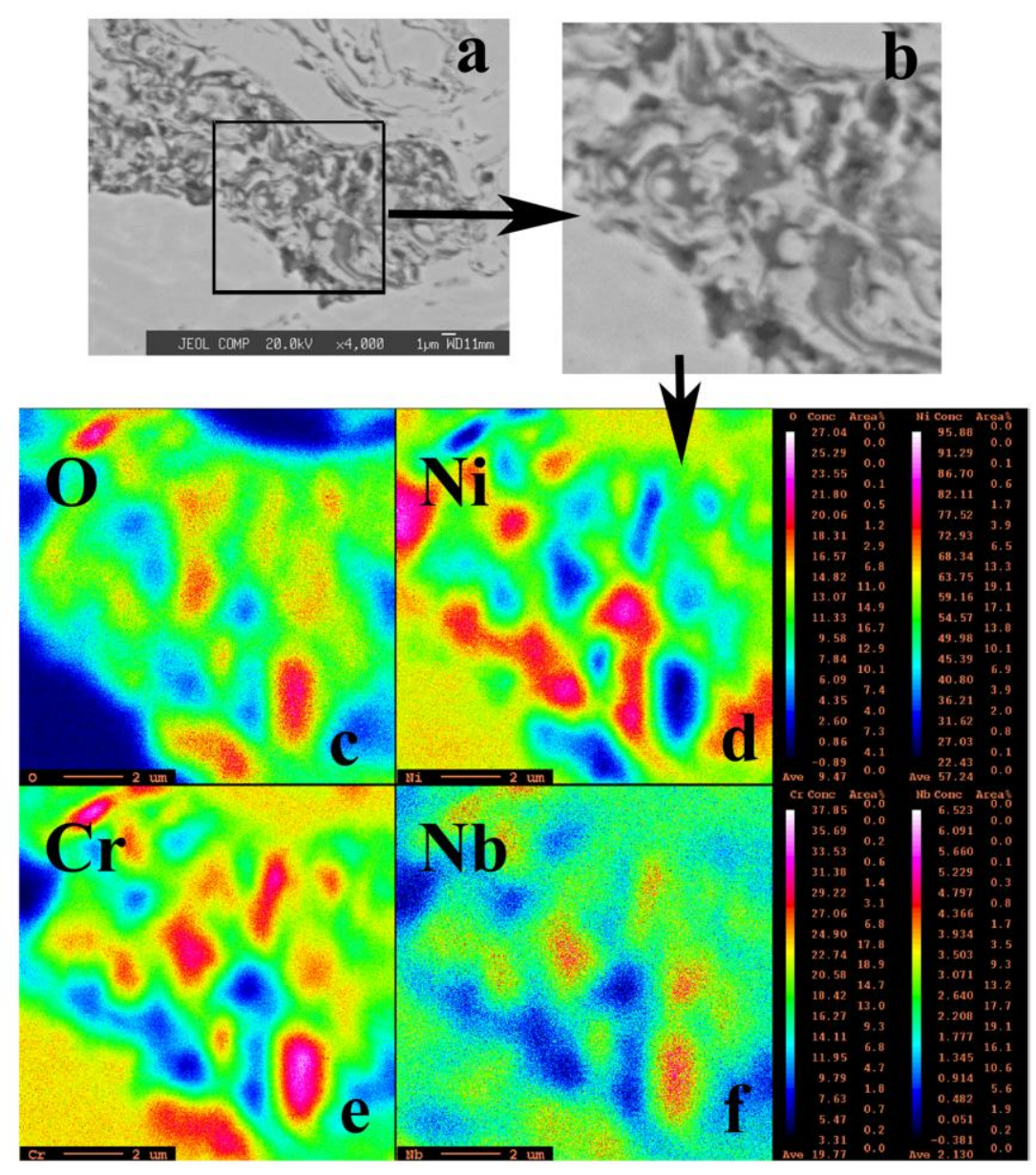




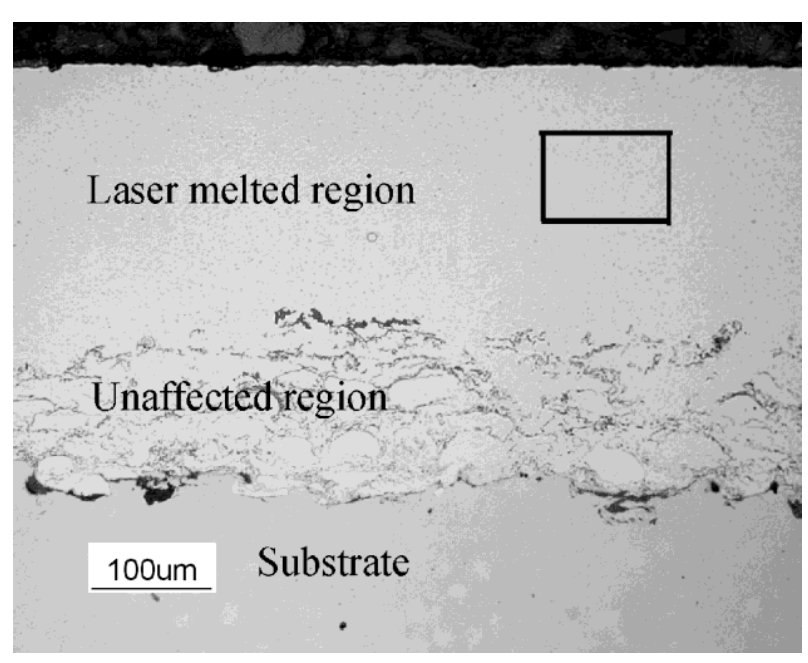




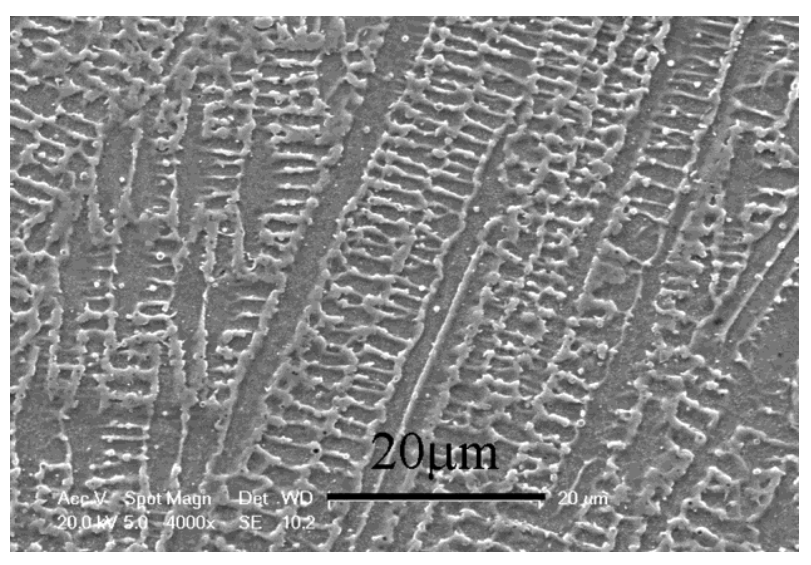




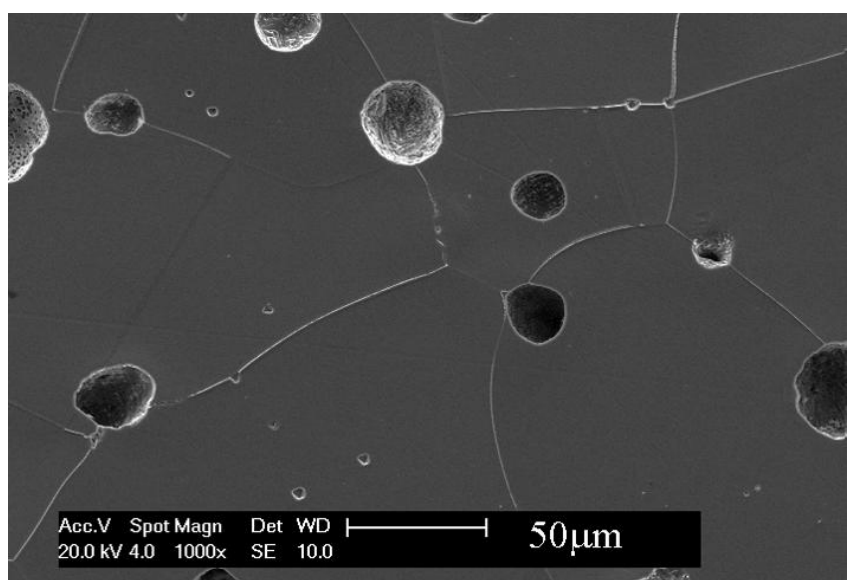




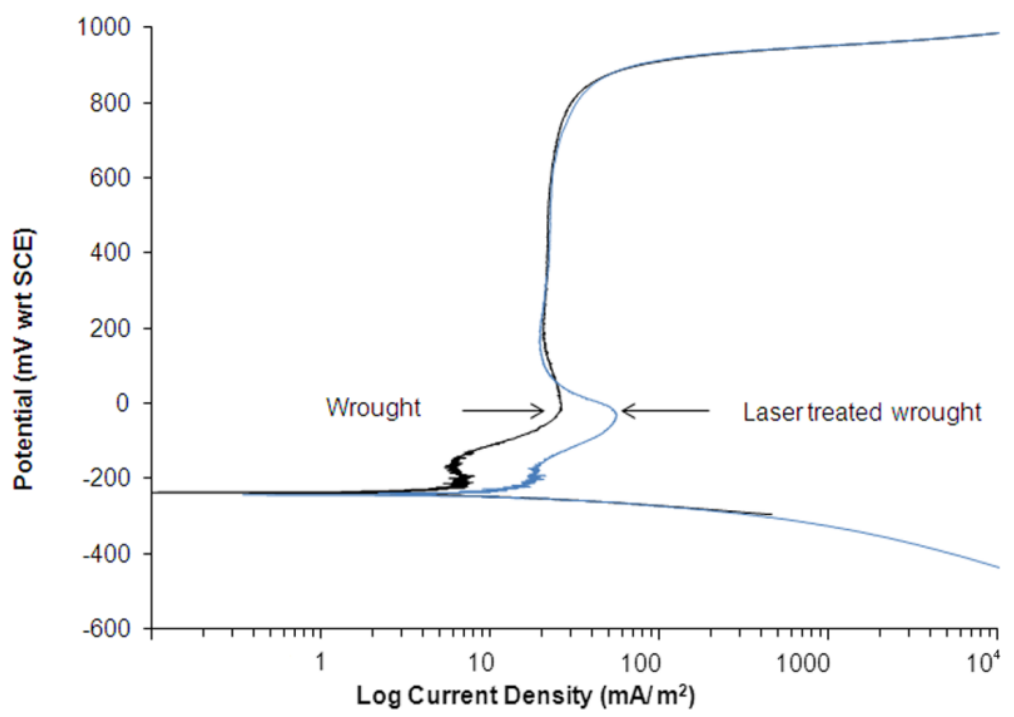




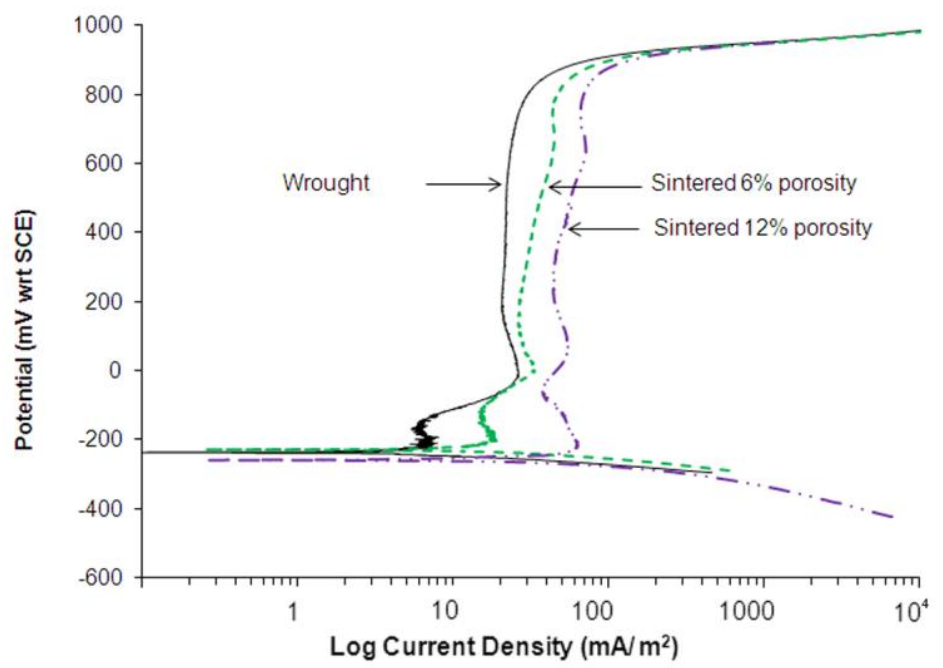




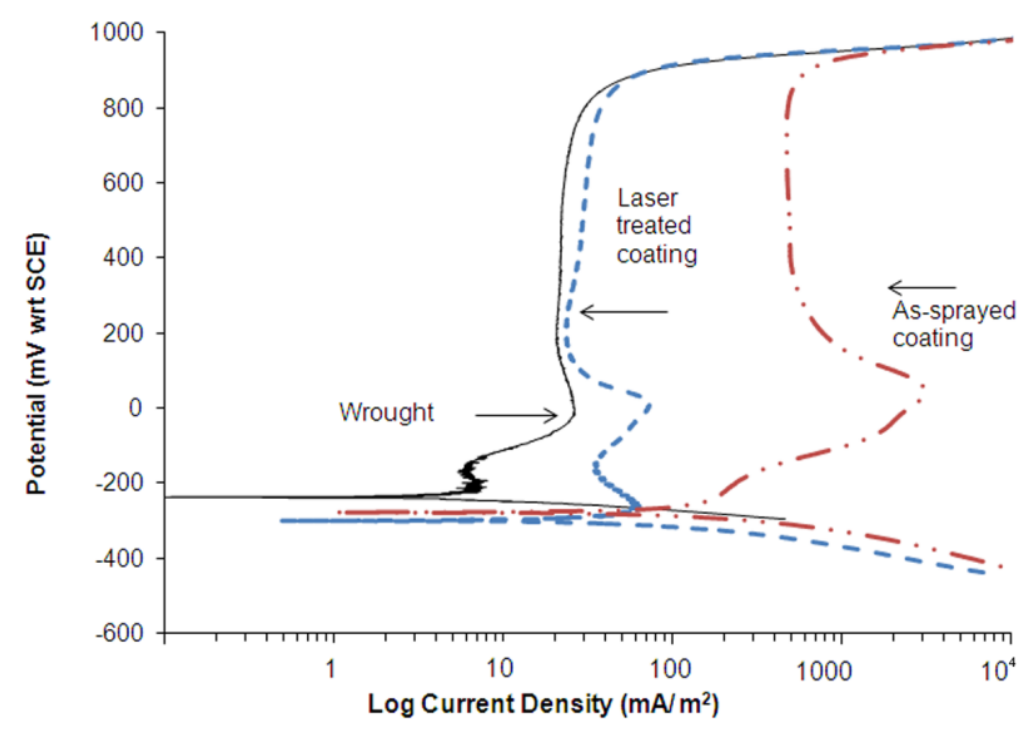




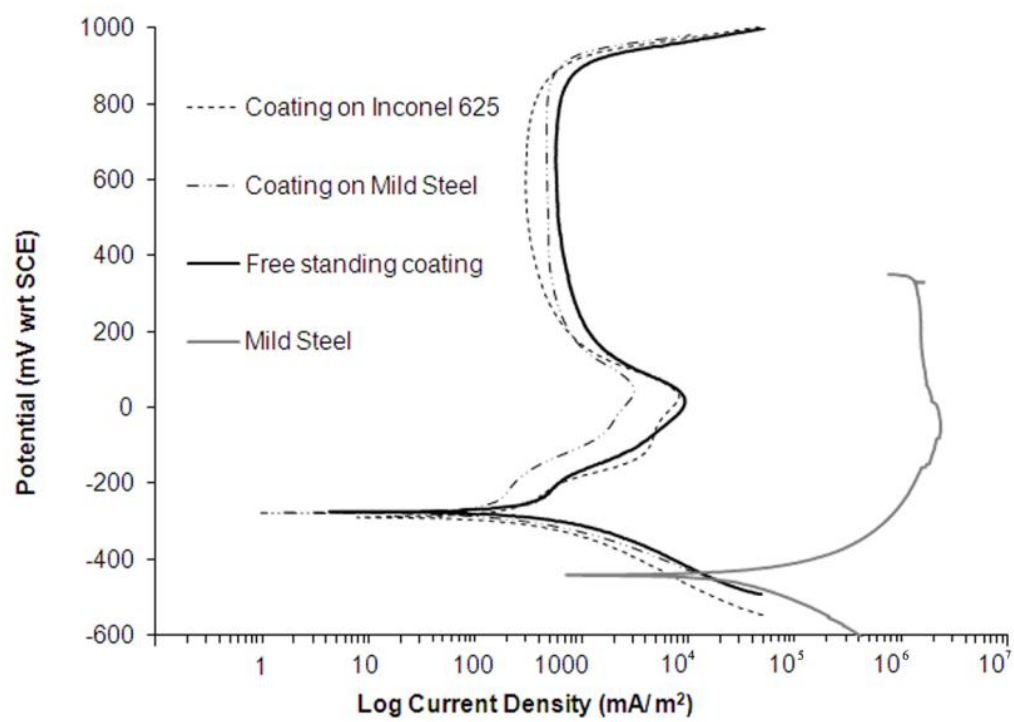




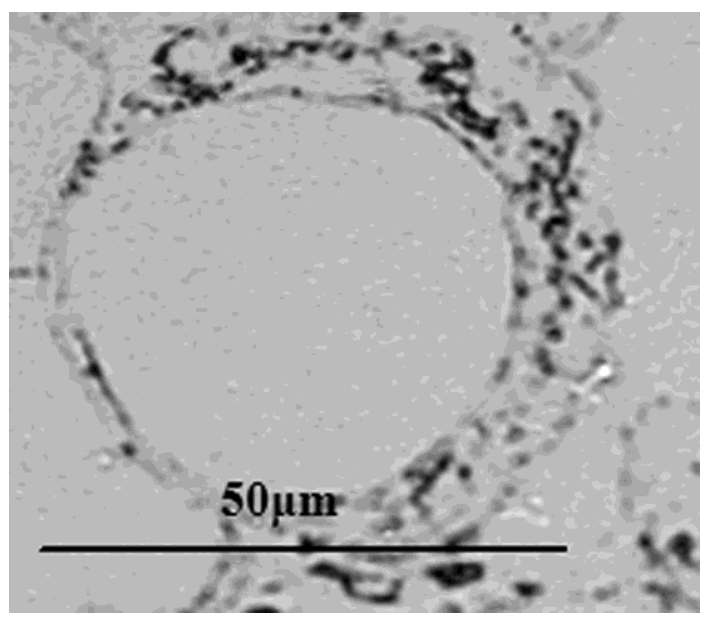




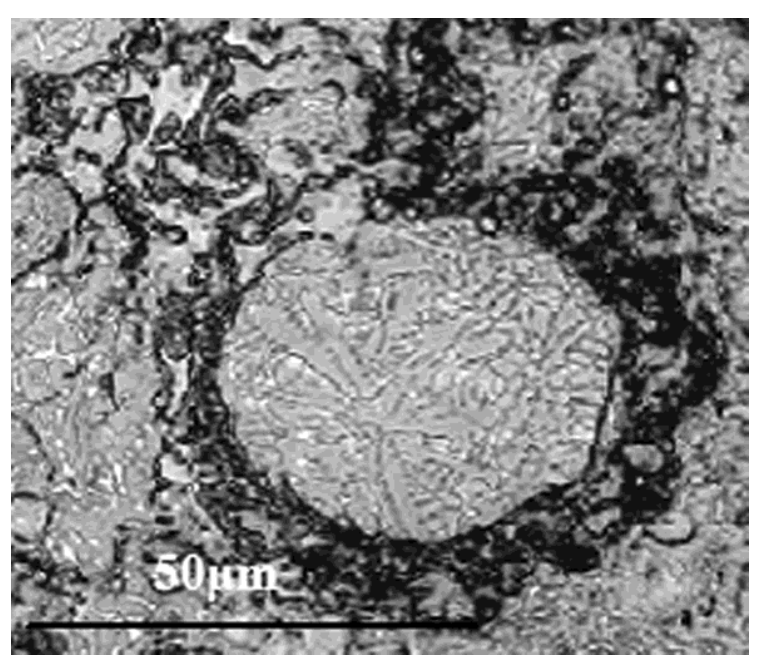

